\title{
The Human Impact on the Ecosystem: Past, Present and Future
}

\author{
Brunetto Chiarelli* \\ * Int. Inst. Humankind Studies - clo Lab. of Anthropology and Etnology University of Florence, \\ Via del Proconsolo 12 - 50123 Firenze (Italy) \\ E-mail: antropos@unifi.it
}

The earliest living forms on Earth originated more than five billion years ago. It was only with the beginning of the Tertiary Age, 75 million years ago, that the first Mammals were developed, and 65 million years ago that the first forms of Primates were differentiated.

The lineage of the Human species originated approximately five million years ago due to the fusion of two acrocentric chromosomes which differentiated hominid karyotype from that of Apes (Chiarelli, 1961).

The genus Homo appeared approximately half a million years ago, while the species Homo sapiens, to which we belong, appeared 200 thousand years ago.

This long adaptive and evolutionary process led to the increasingly dominant impact of human action on Nature. Man, however, began to be aware of Nature only around 10 thousand years ago.

This represents the ecological crisis that led to the cultural transition from the Paleolithic to the Neolithic Era, which was due, almost certainly, to changes in climate and the increased exploitation of the Earth's resources, as a result of farming and animal breeding.

\section{The history of population increase and its needs}

Human beings since their origin, approximately 5 million years ago, need a basic intake of $2.000 \mathrm{kcal}$ per day, from birth to death, independent of sex and living conditions. These $2.000 \mathrm{kcal}$ can be subdivided into the three $F$ which form the basis of "consumerism"1 in a population: Food, Fuel and Fiber.

In our present culture, it is easy to define the nature and quantity of the first $F$ (food) that we use daily, often to excess.

It is more difficult to estimate the energy needed for the second $F$ (fuel), which is invested in movements to collect food or to socialize, or to perform other tasks of daily life and which may be equivalent to walking or running in a savannah environment, or in more recent times travelling on horseback and today travelling in cars. The only difference being the amount of ground covered. We generally give little consideration to the third $F$ (fibres, or clothing). In earliest times, these were non-existent or made of vegetable fibres or animal skins; nowadays they are sophisticated and expensive, especially when considering the material required and the amount of work involved in preparing garments. With this $3 F$ requirement, Humankind from its origins 5 m.y. ago to 2 m.y. ago, not having yet acquired a technological culture, could not surpass 4-5 hundred thousand people, mainly living in the savannah environment of Africa and South Asia with a simple social structure in which females operated mainly as collectors and males as hunters. In the Lower Pleistocene (from 2 million years ago to 780,000 years $B C$ ), due to the development of stone tools, the global population increased from about 800,000 to 1.2 million in the Middle Pleistocene and, further still, to 9 million in the Upper and late Pleistocene (about 10,000-8,000 years BC). Some of this population growth was due to better climatic conditions spreading across the world.

The development of crop-based agriculture and the breeding of animals took place around 8,000-6,000 years $\mathrm{BC}$ and to a large degree met the demands of the first $F$ (food). This led rapidly to the creation of different cultures and an increase in the global population to about 50 million people, over a period of less than a thousand years.

A great change in the growth of populations was caused by the transition from bronze to iron age technologies in the Mediterranean area (Vannini, 2011) which coincided with the inception of the Etruscan culture (Chiarelli, 2010). At the time of Christ, the global population approached 250 million people. At this time, many of the basic norms of social life were accurately defined in a large area under the rule of the Roman Empire. Technologies were poorly developed in the Early Christian Era, and it took 15 centuries for the population to double to 500 million, roughly at the time when Columbus arrived at what is now known as San Salvador. It took only four centuries, until 1835, for the next doubling of the population, to one billion, to occur. Population rose more rapidly as fossil fuels were increasingly exploited (a prime example of the second $F$, fuel) and industrialization took hold. After only 90 more years, in 1925, the human population reached about two billion, and then three billion in 1950, in spite of the disastrous World War II.

The combination of fossil fuels and modern agricultural science enabled huge increases in global food production and by the beginning of the present century six billion people lived on Earth. In 12 years, the global population has now reached seven billion (October 2012). 
If population growth rates are maintained, we should reach a total of nine billion people by year 2040 .

This rapid increase in population, accompanied by increases in industrial development and material consumption, has had significant effects on the world's global ecosystem. Which poses a major problem for the survival of our species. Being a naturalist, I share the view of T. Dobzhansky who often reminded us that, in considering the development of life on Earth, there are more extinct species than there are those still in existence and we may soon be joining that unfortunate former group.

We expect to reach the 10 billion mark before 2050 . Yet, all things considered, population can not grow much beyond this figure due to the present ecological incompatibility between levels of demand and supply of the resources available on planet Earth.

\section{What to do?}

\subsection{Population control}

Obviously, one way of reducing the human impact on the ecosystem is to impose strict controls over birth rates. Which means reducing the probability of the fertilization of the 420 eggs which each human female has during her fertile life. This could be achieved through personal choice, i.e., by observing a vow of abstinence or via the various contraception methods. In Western industrialized countries, awareness of birth and sex control practices contribute to keeping human population growth under control.Additional factors which can contribute to reducing birth rates are increased and equal opportunities of employment for women and better education (including sexual education). Family planning is also a common practice, with no more than two children per family. However, family planning has not been as successful in the so-called developing countries because of a poor knowledge and practice of methods of contraception and because of the scarcity of employment opportunities for women. Moreover, food and medicinal aid have contributed to population survival and increase.

\subsection{Perspectives for an increase of the '3F', towards survival of humankind after reaching 10 billion in 2050}

\subsubsection{Food}

An increase in food production for a population of ten billion people is theoretically possible using various biotechnologies such as genetically modified (GM) organisms. However, current evidence does not support the claim that GM plants actually produce more than appropriately managed traditional farms. Additionally, some GM products are designed only to be effective for one planting, and new seed must be purchased for every new crop. This poses the real danger that a commercial product, such as GM wheat with a 'killer' gene, could place the livelihood of traditional farmers at risk and with little benefits to society at large. Some other examples of GM food include:
- The (theoretically possible) insertion of a lysine (an essential amino acid) producing gene into corn. This would make the amino acid profile of corn more suitable for human consumption and could reduce the demand and consumption of other lysine-rich foods, such as animal meat.

- The use of bacteria in petrol to synthesize proteins that may be consumed as food for humans. However, this approach is problematic because of significant problems of scaling.

Another important factor is to avoid wasting food, either at the time of harvest and storage or at the time of consumption. A significant proportion of food is lost simply because of poor food management.

Perhaps the most important way of ensuring that huge populations can be fed is to develop systems that safeguard equitable food distribution and make sure that food prices do not become prohibitive or susceptible to market manipulation.

\subsubsection{Fuel}

There is a growing tendency to invest in so-called renewable resources that can produce energy. These include solar and wind energy, as is being demonstrated in the Atlas Mountain chain and with the Sahara project. Other sources include hydroelectric power and tidal and geothermal energy. These do not produce $\mathrm{CO}_{2}$ and, therefore, do not contribute to the greenhouse effect. However, they will not replace the convenience and abundance of the energy provided by fossil fuels. A critical problem with fossil fuels is that they are non-renewable and their production over the next few decades will decrease significantly, thus there is a strong impetus to explore all potentially available sources of renewable energy.

\subsubsection{Fiber}

Great possibilities are anticipated regarding the development of synthetic fibre, which will reduce the use of the currently common fibre production processes.

\subsection{Sociological interaction}

The growth of urban populations creates problems of agglomeration and proximity of people. The necessity of changing direction towards a proper social survival must be considered.

Generally speaking, the social organization of any group of mammals follows four stimuli. Two are related to the biology of the species: the mother-child stimulus (A) and the sexual urge (B). The other two are related to the environment in which the population lives: cooperation in the search for food (C) and defense of the group (D). The relationship between these stimuli and the environment $(k)$ determines the best adaptive choice for a social structure. The variety of intensity of the biological stimuli among the different species determines the minimum number of individuals needed for the survival of the population over time (deme), while the productivity of the environment in which the population lives determines the maximum number: 


$$
(A+B)+k(C+D)=\Delta
$$

However, 'culture' which originated in the brain (intelligence) generates the possibility of an increased impact on the ecosystem. Therefore, the previous equation should be:

$$
[(A+B)+\kappa(C+D)]^{i}=\Delta_{H}
$$

Where ei reflects the (negative or positive) impact of culture on the ecosystem. Culture allowed a dramatic increase in population speed of transportation and communication. However, the survival of humankind is still related to the maintenance of biodiversity and the heterogeneity of cultures. In some way, we can foresee the same conditions we had during the Tertiary Age, during which several species of insect developed very complex social structures.

\subsection{Culture}

Compared with animals, present day humans are born with simpler instinct equipment but a greater power of learning and, therefore, have a relatively longer period of dependence on their family. Moreover, due to the development of language, humans can communicate and discuss problems, and relative solutions, with one another passing information down to future generations. Various societies, over long periods of time, have developed a variety of ways of using their powers of learning and instinct, and produced tools to ease their lives and to satisfying biological drives. These solutions are called 'cultures'.

\section{Culture includes:}

- a shared way of perceiving and thinking about the world

- agreed forms of non-verbal communication

- agreed rules and conventions about what should be done in different situations

- agreed morals and values, and a system of religious and allied beliefs

The future possible survival of our species has to consider these different aspects.

\section{Conclusion}

From its origin 5 million years ago, humankind has spread across the globe more effectively than any other single species. It has demonstrated an astonishing ability to adapt to its environment. It has applied its unique gifts of imagination, superior intelligence and creativity to create advanced civilizations and cultures. In so doinghumankind has assumed an attitude of arrogance of superiority over the natural world and has exploited this world to the advantage of humanity. It has been too successful. This exploitation has pushed the world to its biophysical limits and now it is failing. Humanity knows the reason why. Whether the various groups of humans, who make up the constituencies of the world, can come together and work to mitigate the consequences of their actions, is the great question. It is not just a technical question. To a large extent, it is a question attitude, behaviour and culture.

\section{References}

Chiarelli B. 2010. Dal bronzo al ferro: sulla possibile origine anatolica degli Etruschi. In: Systema Naturae, Altravista, Padua, Italy, 10.

Vannini A. 2010. La bussola dei fenici. In: Systemo Noturoe, Altravista, Padua, Italy, 10.

Accademia Pontificia delle Scienze 1993. Popolazioni e Risorse, Report,Accademia Pontificia delle Scienze, Vatican City.

Chiarelli B. 1992. Man, Nature and Ethics. Global Bioethics, 5: 13-20.

Chiarelli B. 2003. The Evolution of Mankind and the Origin of Global Bioethics. Studia Bobolanum, 4.

Chiarelli B. 2003. Dalla Naturo allo Cultura Principi di Antropologia Biologica e Culturale, Piccin, Padua, Italy.

Cipolla C. 1994. Before the Industrial Revolution European Society and Economy: 100 7700, Norton, NewYork, NY.

Cohen J.E. 1995. Population Growth and Earth's Human Carrying Capacity, Science, 269: 341-346.

Heln W.M. 1993. Is Human Culture Carcinogenic for Uncontrolled Growth and Ecological Destruction? BioScience, 43: 768-773.

Jonas L.H. 1990. II principio della responsabilità, Einaudi, Torino, Italy. Lieberman P. 2007. The Evolution of Human Speech: its Anatomical and Neural Bases, Current Anthropology, 48, 1: 39 66.

Leopold A.S. 1949. A Sand Country Almanac, with other Essay on Conservation from Round River. Oxford University Press, Oxford, UK.

Malthus T.R. 1798. An Essay on the Principle of Population. In: Himmelfarb G. (ed.) 1970, On Population, Modern Library, NewYork, NY.

Marchetti C. 1993. 1012:A Check on the Earth-Carrying Capacity for Man, Globol Bioethics, 6.

Potter V.R. 1992. Global Bioethics as a secular source of moral Authority for long term Human survival. Global Bioethics, 5: 5-11.

Soleri P. 1969. Ecology: The City in the Image of Man, MIT Press, Cambridge, MA.

Teilhard de Chardin P. 1956. La place de I homine dans la nature, Seuil, Paris, France.

\section{Notes}

1. Consumerism in Wikipedia has been defined as the equation of personal happiness with the consumption and the purchase of material possessions. In economics, consumerism refers to economic policies placing emphasis on consumption. In an abstract sense, it is the belief that the free choice of consumers, should dictate the economic structure of society. 